\title{
Glacier change in northern Sweden from AD 500: a simple geometric model of Storglaciären
}

\author{
S. C. B. Raper, K. R. Briffa And T. M. L. Wigley* \\ Climatic Research Unit, University of East Anglia, Norwich NR4 7TH, England
}

\begin{abstract}
A simple geometric model of glacier volume is derived. The model is based on the assumption that the net mass balance averaged over the glacier surface is related to the summer temperature and winter accumulation at a representative height on the glacier. This height varies with time as climate changes, in ways that are determined by the geometry of the glacier surface. Expressions are derived for the equilibrium glacier volume $\left(V_{\mathrm{eq}}\right)$ as a function of summer temperature and winter accumulation and for the glacier-response time $(\tau)$ as a function of volume.

The model is used to reconstruct the volume of Storglaciären over the period AD 500-1992. Measured net mass-balance data for Storglaciren (1946-92) are used to estimate the model parameters. For the summer temperature forcing, the long treering-based temperature reconstruction for northern Fennoscandia is used to extend a temperature record near the glacier back to AD 500. For the past accumulation forcing, a range of assumptions is tested.

The results show that the prime cause of the decrease in volume of Storglaciären between 1946 and 1992 was relatively low accumulation over 1946-89 as opposed to warm temperatures as previously supposed. Reconstructed volume changes agree well with geomorphological evidence. Where differences occur, deductions can be made about past accumulation. For example, the maximum reconstructed glacier volume is associated with the cold period from 1580 to 1740 but relatively low accumulation probably limited the volume to values not much larger than that achieved around 1916 .
\end{abstract}

\section{INTRODUGTION}

This paper describes a simple geometric glacier model derived in order to investigate glacier responses to climate change. Previous attempts to simulate historical glacier variations have been based on one-dimensional numerical ice-flow models forced by glacier mass-balance history. The limited success of these attempts has been ascribed to deficiencies in the mass-balance histories (Greuell, 1992). Here we take advantage of a long summer temperature reconstruction based on tree rings. The simplicity of our model allows different assumptions about past accumulation to be explored.

Our purpose is two-fold. First, the insight that we gain from the model will aid in the study of probable future contributions of glacier melt to sea-level change. Secondly, by comparing a tree-ring-based reconstruction of ice-volume changes for a particular northern Swedish glacier with the fragmentary and less precisely resolved record of glacier changes derived from moraine dates, we can gain some insight into the limitations associated with regional climate histories deduced from such data.

\footnotetext{
* Present address: UCAR/NCAR, P.O. Box 3000, Boulder, Colorado 80307-3000, U.S.A.
}

\section{LIST OF SYMBOLS}

$h$

$h^{*}$

$h^{*} \mathrm{R}$

$h_{z} \quad$ Height of the fixed temperature station relative to the top of the glacier $(\mathrm{m})$

$m \quad$ Index relating $h^{*}$ and $A$

$n \quad$ Index relating $A$ and $V$

$t \quad$ Time

A Annual mean surface area of glacier $\left(\mathrm{m}^{2}\right)$

$A_{\mathrm{R}} \quad$ Reference glacier area $\left(\mathrm{m}^{2}\right)$

$B \quad$ Annual net mass balance at a specific point on the glacier surface $\left(\mathrm{m}_{\text {year }}{ }^{-1}\right)$

$\bar{B} \quad$ Annual net mass balance averaged over the glacier $\left(\mathrm{m}_{\text {year }}{ }^{-1}\right)$

$B_{\mathrm{T}} \quad$ Annual net mass balance at the terminus $(\mathrm{m}$ year $^{-1}$ )

$C$ Accumulation at a fixed location $\left(\mathrm{m}_{\text {year }}{ }^{-1}\right.$ )

$C_{\mathrm{R}} \quad$ Reference accumulation at a fixed location $\left(\mathrm{m}_{\text {year }}{ }^{-1}\right)$

$\Delta C \quad C-C_{\mathrm{R}}\left(\right.$ m year $\left.^{-1}\right)$

$D \quad$ Mean depth of glacier $(\mathrm{m})$

$D_{\mathrm{R}} \quad$ Reference value of $D(\mathrm{~m})$

$K \quad$ A constant $\left(\right.$ m year $\left.^{-1}\right)$ 
$L \quad$ Mean length of glacier $(\mathrm{m})$

$T$ Summer temperature at height $h_{z}\left({ }^{\circ} \mathrm{C}\right)$

$T_{\mathrm{R}} \quad$ Reference value of $T\left({ }^{\circ} \mathrm{C}\right)$

$\Delta T \quad T-T_{\mathrm{R}}\left({ }^{\circ} \mathrm{C}\right)$

$V \quad$ Annual mean glacier volume $\left(\mathrm{m}^{3}\right)$

$V_{\text {eq }} \quad$ Equilibrium glacier volume $\left(\mathrm{m}^{3}\right)$

$V_{\mathrm{R}} \quad$ Reference value of $V_{\mathrm{eq}}\left(\mathrm{m}^{3}\right)$

$Y \quad V^{n / m}\left(\mathrm{~m}^{3}\right)$

$Y_{\text {eq }} \quad V_{\text {eq }}^{n / m}\left(\mathrm{~m}^{3}\right)$

$\alpha \quad$ Parameter relating temperature to ablation $\left(\mathrm{m}\right.$ year ${ }^{-1} \mathrm{C}^{-1}$ )

$\beta \quad$ Altitudinal gradient of accumulation $\left(\right.$ year $^{-1}$ )

$\Gamma \quad$ Altitudinal lapse rate $\left({ }^{\circ} \mathrm{Cm}^{-1}\right)$

$\alpha \Gamma \quad$ Altitudinal gradient of ablation $\left(\right.$ year $^{-1}$ )

$\tau \quad$ Glacier-response time (year)

$\tau_{\mathrm{R}} \quad$ Reference value of $\tau$ (year)

\section{THE MODEL}

\section{a. Derivation of the model equation}

Our derivation starts from the usual requirement that the change in glacier volume $(V)$ with time $(t)$ is equal to the surface area of the glacier multiplied by the areaaveraged net mass balance,

$$
\mathrm{d} V / \mathrm{d} t=A \bar{B}
$$

where $A$ is the annual mean surface area $\left(\mathrm{m}^{2}\right)$ and $\bar{B}$ is the annual net mass balance averaged over the whole glacier $\left(\mathrm{m}^{-1}\right.$ year $\left.{ }^{-1}\right)$. The density of the glacier ice is assumed to be constant.

Paterson (1994) defined the steady-state dimensions of a glacier as those that would result from an areaaveraged zero mass balance over many years. As a result of glacier dynamics, $V(t)$ generally approaches equilibrium more rapidly than the mean length, $L(t)$, though ultimately steady state is reached at the same time. For the derivation of our model, however, we assume that for a given glacier volume the shape of the glacier is the same whether the glacier is in advance, retreat or equilibrium. In other words, we assume that the relative values of $V, A$ and $L$ for each $V$ do not differ significantly from their steady-state values as defined by Paterson (1994). It follows that we also assume fixed basal topography.

Kuhn (1981) showed that the variation of the ELA in response to climate changes is governed by the altitudinal gradients of the accumulation and ablation. Here, we assume that the datum accumulation increases linearly with altitude, but for simplicity time-dependent accumulation variations are taken to be uniform in space. For the ablation, we assume that it is related to the summer temperature and decreases linearly with altitude. We also assume that the altitudinal gradients of accumulation and ablation are temporally invariant. A refinement would be to assume that the altitudinal gradient of accumulation increased when accumulation increased but this is not attempted here, though we do investigate the uncertainties associated with the assumed value of the gradient.

When a glacier is in steady state, or equilibrium with the prevailing climate conditions, the net mass balance averaged over the glacier as a whole is zero and the ELA does not vary with time. For the non-equilibrium case, we can still define a representative height on the glacier surface, $h^{*}$, where the specific net mass balance is equal to the specific net mass balance averaged over the whole glacier (the latter being non-zero in general). We assume here that the height of the top of the glacier is fixed and identify heights on the glacier surface relative to the top of the glacier. The heights, $h$, are thus measured positive down from the (fixed) height of the top of the glacier as shown in Figure 1. The height, $h^{*}$, is governed by the altitudinal distribution of the glacier area.

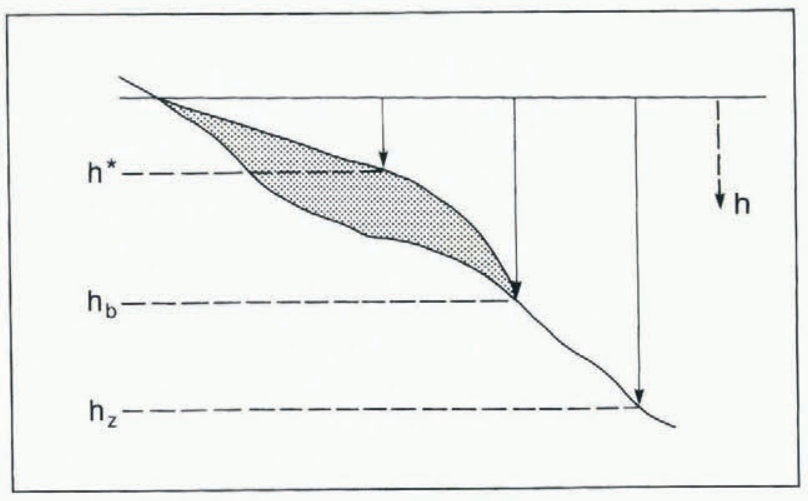

Fig. 1. Schematic cross-section of a glacier showing elevations relative to the top of the glacier (positive downwards): viz. the representative height $\left(h^{*}\right)$, the bottom of the glacier $\left(h_{\mathrm{b}}\right)$ and the height of a fixed temperature station $\left(h_{z}\right)$.

Given a glacier in a datum or reference state with a reference glacier volume, $V_{\mathrm{R}}$, with area, $A_{\mathrm{R}}$, and representative height, $h_{\mathrm{R}}^{*}$, we assume that we can define a reference summer temperature, $T_{\mathrm{R}}$, and accumulation, $C_{\mathrm{R}}$ (m year $\left.^{-1}\right)$, such that the specific net mass balance averaged over the glacier equals the specific net mass balance at $h_{\mathrm{R}}^{*}$ and can be expressed as

$$
B=\Delta C-\alpha \Delta T
$$

where $\alpha$ is a parameter relating temperature to ablation and has units myear ${ }^{-1} \mathrm{C}^{-1}, \Delta T$ is a temperature anomaly given by $T-T_{\mathrm{R}}$ and $\Delta C$ is an accumulation anomaly given by $C-C_{\mathrm{R}}$. At equilibrium, $\Delta C$ equals $\alpha \Delta T$. Because we are only interested in the temperature and accumulation anomalies, $T-T_{\mathrm{R}}$ and $C-C_{\mathrm{R}}$ may be measured at any nearby location, for example, at a local meteorological station at height $h_{z}$ (Fig. 1). Due to spatial inhomogeneities in measured accumulation, one may have to adjust the measured accumulation so that it represents accumulation conditions on the glacier. Such adjustments are not needed for temperature.

As the glacier area changes, the representative height, $h^{*}$, will change accordingly. Thus, as the glacier becomes larger and extends to lower altitudes, so $h^{*}$ will move downslope and as the glacier contracts $h^{*}$ will move upslope. If $\beta$ and $\alpha \Gamma$, where $\Gamma$ is the temperature lapse 
rate, are the altitudinal gradients of accumulation and ablation, using Equation (2), the net specific mass balance at $h^{*}$ is given by

$$
B=\Delta C+\beta\left(h_{\mathrm{R}}^{*}-h^{*}\right)-\alpha\left(\Delta T-\Gamma\left(h_{\mathrm{R}}^{*}-h^{*}\right)\right) .
$$

Re-arranging Equation (3) and substituting in Equation (1) gives

$$
\mathrm{d} V / \mathrm{d} t=A\left(\Delta C-\alpha \Delta T+(\beta+\alpha \Gamma)\left(h_{\mathrm{R}}^{*}-h^{*}\right)\right) .
$$

The mechanism by which the glacier comes to equilibrium may be viewed as follows. Assuming the glacier starts in equilibrium, an increase in $\Delta C$ or a decrease in $\Delta T$ will cause a positive mass balance. The glacier will respond by increasing its volume and $h^{*}$ will descend down the mountain. The altitudinal gradients in accumulation and ablation represented by $\beta$ and $\alpha \Gamma$ will cause the mean specific mass balance to return to zero as $h^{*}$ descends.

It is necessary now to find quantifiable expressions for $h^{*}$ and $A$. Given the glacier-shape assumptions made previously, the surface area of the glacier, $A$, may be assumed to be a function of the height $h^{*}$ for which we use the general one-parameter form

$$
A / A_{\mathrm{R}}=\left(h^{*} / h_{\mathrm{R}}^{*}\right)^{m} .
$$

Similarly, we express the area in terms of the volume as

$$
A / A_{\mathrm{R}}=\left(V / V_{\mathrm{R}}\right)^{n} .
$$

Thus, combining Equations (5) and (6) and rearranging gives:

$$
h^{*}=h_{\mathrm{R}}^{*}\left(V / V_{\mathrm{R}}\right)^{n / m}
$$

The parameters $m$ and $n$ define the changing threedimensional shape of the glacier. They are governed by the basal topography and ice-flow dynamics. Because we assume that, for a particular volume, the shape of the glacier is the same whether it is in advance or retreat, $m$ and $n$ are independent of the mass balance. The parameter $m$ defines the vertical movement of the representative height $h^{*}$ relative to the glacier area. It therefore controls the relationship between the changing glacier average width and length. The parameter $n$ represents the change in glacier depth with glacier volume (see section 3c for details).

Using Equations (4) and (6) and substituting Equation (7) for $h^{*}$, gives our final model equation

$$
\begin{aligned}
\mathrm{d} V / \mathrm{d} t=A_{\mathrm{R}}\left(V / V_{\mathrm{R}}\right)^{n}[\Delta C-\alpha \Delta T & \\
& \left.+(\beta+\alpha \Gamma) h_{\mathrm{R}}^{*}\left(1-\left(V / V_{\mathrm{R}}\right)^{n / m}\right)\right] .
\end{aligned}
$$

\section{b. Equilibrium volume and response-time formulation}

Because $\mathrm{d} V / \mathrm{d} t=0$ at equilibrium, Equation (8) becomes

$$
0=\left[\Delta C-\alpha \Delta T+(\beta+\alpha \Gamma) h_{\mathrm{R}}^{*}\left(1-\left(V_{\mathrm{eq}} / V_{\mathrm{R}}\right)^{n / m}\right)\right] .
$$

Hence

$$
V_{\mathrm{eq}}=V_{\mathrm{R}}\left[1+(\Delta C-\alpha \Delta T) /\left((\beta+\alpha \Gamma) h_{\mathrm{R}}^{*}\right)\right]^{m / n} .
$$

Equation (9) defines the equilibrium volume, $V_{\text {eq }}$, in terms of the accumulation and temperature anomalies relative to the reference values $T_{\mathrm{R}}$ and $C_{\mathrm{R}}$. The form of the $V_{\text {eq }}$ versus $\Delta C$ and $\Delta T$ relationship is thus governed by the index $m / n$. It follows from Equation (9) that $V_{e q}=V_{\mathrm{R}}$ when $\Delta C=\alpha \Delta T$. Equation (9) also shows that $V_{\text {eq }}=0$ when $(\Delta C-\alpha \Delta T)=-(\beta+\alpha \Gamma) h_{\mathrm{R}}^{*}$, i.e. when the change in specific net mass balance is such that the ELA coincides with the top of the glacier. When $(\Delta C-\alpha \Delta T)<-(\beta+\alpha \Gamma) h_{\mathrm{R}}^{*}$, Equation (9) has no meaningful physical interpretation.

The model given by Equation (8) can now be written in terms of the equilibrium volume by re-arranging and substituting $V_{\text {eq }}$ from Equation (9). This gives

$\mathrm{d} V / \mathrm{d} t=A_{\mathrm{R}}\left(V / V_{\mathrm{R}}\right)^{n} \cdot K\left[\left(V_{\text {eq }} / V_{\mathrm{R}}\right)^{n / m}-\left(V / V_{\mathrm{R}}\right)^{n / m}\right](10 \mathrm{a})$ where

$$
K=(\beta+\alpha \Gamma) h_{\mathrm{R}}^{*}
$$

is a constant with units of $\mathrm{m}_{\text {year }}{ }^{-1}$. If we now define a volume variable, $Y$, by

$$
Y=V^{n / m}
$$

then Equation (10a) may be written in more conventional linear-response form involving a time-scale $\tau$ as

$$
\mathrm{d} Y / \mathrm{d} t=\left(Y_{\mathrm{eq}}-Y\right) / \tau
$$

where $Y$ and $Y_{\mathrm{eq}}$ are $V^{n / m}$ and $V_{\mathrm{eq}}^{n / m}$, respectively, and

$$
\tau=(m / n)\left(V_{\mathrm{R}} / A_{\mathrm{R}}\right)(1 / K)\left(V / V_{\mathrm{R}}\right)^{(1-n)-(n / m)}
$$

the parameter $\tau$ may be identified as a glacier-response time with units year.

\section{c. Assigning values for $m$ and $n$}

In this section we show how the parameters $m$ and $n$ govern the relationships between the average depth, width and length of the glacier for different volumes.

Consider $n$ first. Equation (6) shows that $n$ controls the relationship between area and volume and hence the mean depth versus volume relationship. When $n=1$, the glacier depth is a constant for all volumes, which is clearly unrealistic. More realistically, as the glacier volume increases from zero, glacier depth should increase first quite rapidly and then more slowly. This implies $n<1$; sensible behaviour is given by $n$ in the range $0.6-0.8$.

The parameter $m$ defines how the representative height $h^{*}$ varies with glacier area. The movement of $h^{*}$ depends on the altitudinal distribution of the glacier area and how that changes with changing volume. Consider some examples where the surface slope of the glacier is uniform, so that $m$ governs the relationship between the mean glacier width and length. Then, when $m=1.0$, the mean glacier width is a constant for all volumes. An increase in area for a parallel-sided glacier will then occur through the extension of the glacier to lower altitudes. When $m=2.0$, the mean glacier width increases in proportion to its length. In this case, a parallel-sided glacier would increase both in width and length with an increase in area. Since valley glaciers have generally very steep sides, an appropriate 
value for $m$ for a glacier with near-parallel sides is about 1.0. For a steep-sided triangular-shaped glacier, which fans out in a linear fashion with decreasing altitude, the appropriate value for $m$ is about 2.0. A non-uniform glacier-surface profile will modify the above appropriate values for $m$.

\section{d. Interpretation of the response-time expression}

The response time of a glacier $(\tau)$ may be defined as the $e$-folding time for the volume of a glacier to adjust from an initial equilibrium state to a new equilibrium state in response to a small step change in mass balance (cf. Jóhannesson and others, 1989b). First, we observe that the $\tau$ given by our Equation (12) is not a constant but is a function of the glacier volume $(V)$. This is a direct consequence of the non-linear equation for $V$ which we have derived. A constant $\tau$ can only arise in the ideal case of a linear first-order system with a pure exponential solution to the step-forcing case, and is clearly unlikely in the case of complex systems like glaciers which vary their geometry with changing size. Secondly, we observe that our expression for $\tau$ contains the ratio $m / n$ which is the index governing the form of the relationship between the equilibrium glacier volume and climate. Hence, $\tau$ involves not only the current geometry of the glacier but also how that geometry will change with changing climate.

Jóhannesson and others (1989a) and Paterson (1994) have put forward the following expression for the response time

$$
\tau=H /-B_{\mathrm{T}}
$$

where $H$ is the maximum thickness and $-B_{\mathrm{T}}$ is the mass balance at the terminus. In the case of ice caps and those glaciers whose lateral extension is constrained by very steep sides, our expression for the response time is similar to Equation (13). To show this, consider a glacier in its reference state, so that $V=V_{\mathrm{R}}$ and $A=A_{\mathrm{R}}$. Our Equation (12) may then be written as .

$$
\tau=\left(D_{\mathrm{R}} / n\right) /(K / m)
$$

where $D_{\mathrm{R}}=V_{\mathrm{R}} / A_{\mathrm{R}}$ is the mean glacier depth. First, because $n$ is less than 1.0 (about $0.6-0.8$ ), $D_{\mathrm{R}} / n$ is similar to the maximum thickness scale $H$. Secondly, because $h_{\mathrm{R}}^{*} / m$ is approximately the vertical distance from the ELA (by definition coincident with $h_{\mathrm{R}}^{*}$ ) to the terminus and because the remaining term in $K$, namely $(\beta+\alpha \Gamma)$, is the mass-balance gradient, it follows that $(K / m)$ is approximately equal to $-B_{\mathrm{T}}$.

As a consequence of our steady-state glacier shape assumption used in the derivation of our expression for the response time, Equation (12) probably somewhat overestimates the true response time. In reality, because of the delayed response of the ice dynamics, an increase decrease in temperature or accumulation will initially increase/decrease the slope of the glacier surface so that, given the altitudinal dependence of ablation and accumulation, the volume change will be hastened. This also applies to Equation (13).

\section{APPLICATION OF THE MODEL TO STORGLACIÄREN}

\section{a. Storglaciären volume from mass-balance data over $1946-92$}

Storglaciären is a small continental glacier situated in the Tarfala region of the Kebnekaise mountains and covers an altitude range between about 1135 and $1720 \mathrm{~m}$ a.s.l. Winter and summer balances on this glacier have been measured year-by-year since 1946 (Fig. 2a, b), measurements that provide the longest direct record of glacier mass balance in the world. These data are regularly published by the University of Stockholm (e.g. Bodin, 1993). The average net mass balance over 1946-92 was

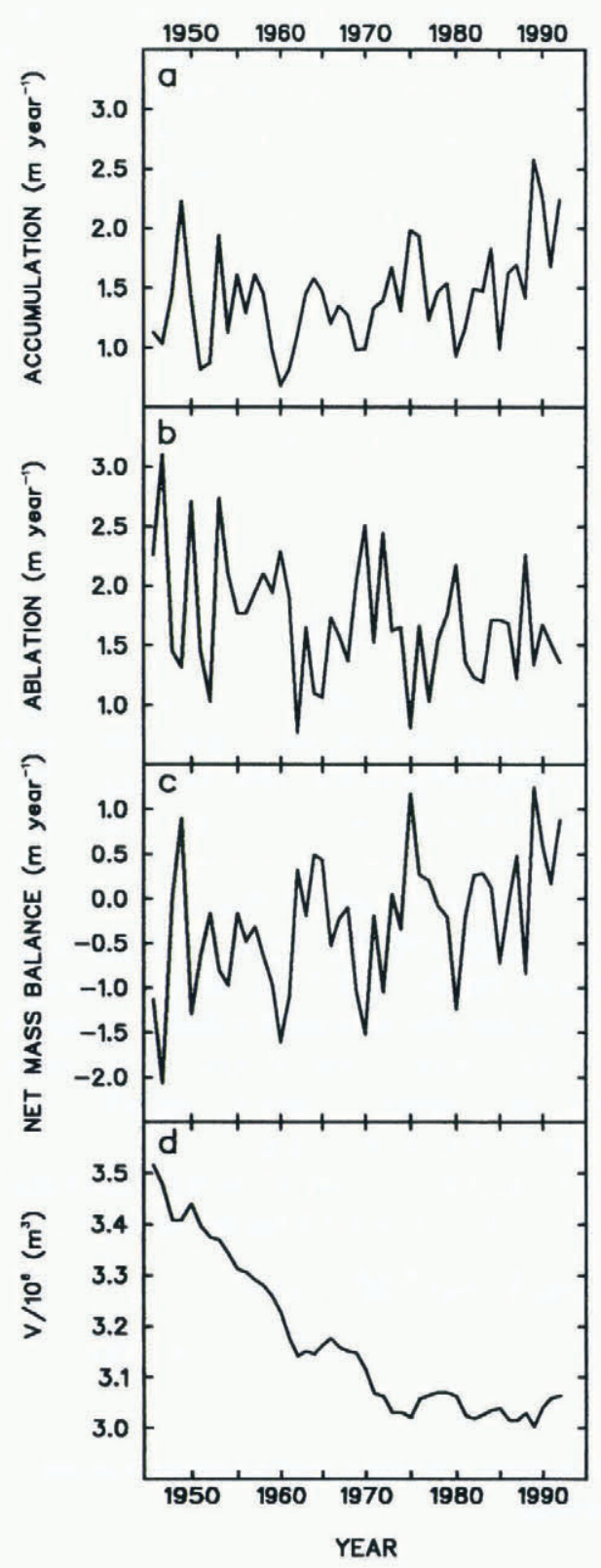

Fig. 2. Time series of (a) accumulation (winter balance), (b) ablation (the negative of the summer balance) and (c) net mass-balance data for Storglaciären 1946-92 (Bodin, 1993, updated). (d) Estimated volume changes for Storglaciären obtained from the net mass-balance data using Equation (15) and $n=0.7$. 
negative and the data display an overall upward trend from negative to slightly positive values (Fig. 2c).

In 1979, the surface area of Storglaciären was measured as $3.1 \times 10^{6} \mathrm{~m}^{2}$ and its mean thickness estimated as $99 \mathrm{~m}$, giving a volume estimate of $3.1 \times 10^{8} \mathrm{~m}^{3}$ (Holmlund and Eriksson, 1989). We use these 1979 estimates of the volume and area together with the massbalance data to derive the history of Storglaciären volume changes. Equations (1) and (6) yield

$$
\mathrm{d} V / \mathrm{d} t=A_{\mathrm{R}}\left(V / V_{\mathrm{R}}\right)^{n} \bar{B}
$$

where $A_{\mathrm{R}}$ and $V_{\mathrm{R}}$ are the area and volume in 1979. (Note that $A_{\mathrm{R}}$ and $V_{\mathrm{R}}$ should be steady-state values; this is a reasonable assumption (Holmlund, 1988).) For $n$ we use the range $0.6-0.8$.

Integrating Equation (15) using annual $\bar{B}$ data gives $V(t)$. Over the short period considered here, these results are virtually independent of $n$. Results for $n=0.7$ (Fig. $2 \mathrm{~d}$ ) show that the volume decreased by $0.45 \times 10^{8} \mathrm{~m}^{3}$ over 1946-92. The results agree well with the shorter record of Holmlund (1987).

\section{b. Extension of the Tarfala temperature record}

A long series of temperature estimates representing average "summer" (June-August) conditions over a large region of northern Fennoscandia has been derived by Briffa and others $(1990,1992)$. This reconstruction is based on well-replicated ring-width and wood-densitometric data, precisely dated and averaged to produce continuous chronologies extending from the present back to before AD 500. These chronologies basically represent changing summer warmth. Formal regression calibration and verification procedures have demonstrated that the reconstructed temperature series captures about $50 \%$ of the variance (at both high and low frequencies) of regional mean northern Fennoscandian temperatures (Briffa and others, 1992).

Here, the tree-ring temperature record was adjusted to have the same mean and standard deviation as the Tarfala Research Station June-August mean temperature record over their period of overlap. Figure 3 shows the adjusted proxy temperatures and the Tarfala records for the overlap period, 1946-80. The correlation between

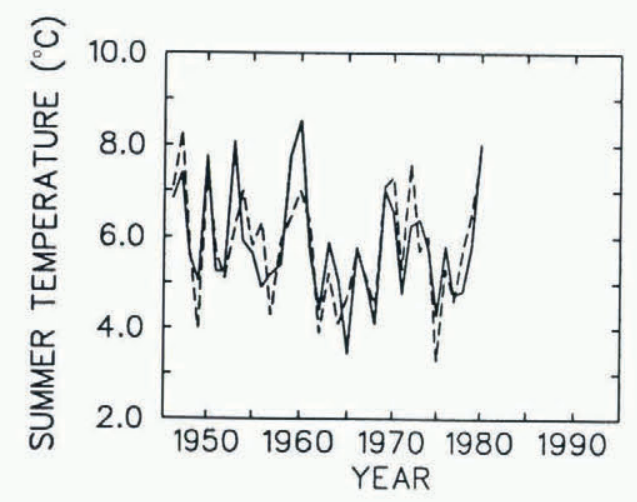

Fig. 3. Comparison of the Tarfala summer-temperature record (dashed) with the adjusted tree-ring temperature data (solid) for the overlap period 1946-80. the two series is 0.76 . To force the glacier model, we use the adjusted tree-ring record for AD 500-1945 attached to the summer Tarfala temperature record over 1946-92.

\section{c. Estimating the model parameters and past accumulation assumptions}

We chose the 1990 volume and area as our reference parameters $V_{\mathrm{R}}$ and $A_{\mathrm{R}}$. This does not imply that the mass balance in 1990 was necessarily zero; in fact, it was slightly positive. It rather implies that $V_{\mathrm{R}}$ and $A_{\mathrm{R}}$ are the volume and area associated with a zero mass balance at height $h_{\mathrm{R}}^{*}$. The values of $V_{\mathrm{R}}$ and $A_{\mathrm{R}}$ are then 3.04 $\times 10^{8} \mathrm{~m}^{3}$ and $3.08 \times 10^{6} \mathrm{~m}^{2}$, respectively. At equilibrium, the reference height, $h_{\mathrm{R}}^{*}$, coincides with the height of the ELA. Since the net mass balance averaged over the glacier is then zero, $h_{\mathrm{R}}^{*}$ can be estimated from Schytt's (1981) relationship between the area-averaged net mass balance and the height of the ELA for Storglaciären. Using data to 1992, the correlation coefficient between the ELA and $\bar{B}$ is -0.88 . Regression analysis then gives the height of the ELA when $\bar{B}=0$ as $1460 \mathrm{~m}$. The corresponding estimate of $h_{\mathrm{R}}^{*}$ (which is measured from the top of the glacier) is then $260 \mathrm{~m}$. In the final analysis, we allow for an uncertainty in $h_{\mathrm{R}}^{*}$ of $\pm 50 \mathrm{~m}$.

For the purposes of this study, we equate the model accumulation and ablation with the fixed-date winter and summer balance, although they are not precisely the same thing (Paterson, 1994). This has to be borne in mind in the interpretation of the results. The altitudinal gradients of accumulation and ablation, represented by the parameters $\beta$ and $\alpha \Gamma$, can then be estimated directly from observed altitudinal data for Storglaciären. We use $\beta=0.005 \pm 0.002$ year $^{-1}$ and $\alpha=0.5 \pm 0.1 \mathrm{~m}$ year $^{-1}{ }^{\circ} \mathrm{C}^{-1}$, with $\Gamma=0.007^{\circ} \mathrm{C} \mathrm{m}^{-1}$ based on Oerlemans (1992). The validity of the chosen values for $\alpha$ is confirmed by examining the temporal summer-balance data as described below. There is no equivalent check for $\beta$. Since the altitudinal gradient of accumulation/winter balance tends to increase with increased accumulation, we have used a larger uncertainty for $\beta$.

Our estimation of the value of the reference parameter $T_{\mathrm{R}}$ is based on the available temporal summer-balance data for Storglaciären over 1946-92 (Fig. 2b). Using the summer temperature data from Tarfala, the mean value of the estimated summer balance over 1946 92 is determined by $T_{\mathrm{R}}$ and the standard deviation by $\alpha$. For $\alpha=0.4,0.5,0.6 \mathrm{~m}_{\text {year }}{ }^{-1}{ }^{\circ} \mathrm{C}^{-1}$, the corresponding values of $T_{\mathrm{R}}$ are $1.6,2.3,2.8^{\circ} \mathrm{C}$. These values of $\alpha$ give ablation summer-balance standard deviations of $0.46,0.57,0.69$ myear $^{-1}$ compared with the observed value of 0.50 $\mathrm{m}_{\text {year }}{ }^{-1}$. The correlation coefficients between the estimated and observed ablations are then in the range 0.93 0.94 . For $C_{\mathrm{R}}$, since no long-term nearby proxy data are available, we assume that the accumulation is measured at $h_{\mathrm{R}}^{*}$ so that $C_{\mathrm{R}}=0$.

The absence of long-term past accumulation/winterbalance data means that we are only able to reconstruct the summer temperature-dependent part of the past glacier-volume changes. Different assumptions can be made about the past accumulation (at height $h_{\mathrm{R}}^{*}$ ), upon which the reconstructions are dependent. For example, we can assume that the past accumulation was temporally 
a constant or we can assume that there is some degree of dependence between the winter balance and summer temperature. The latter would occur if warm summers tended to be associated with warm winters and vice versa. There is some evidence for this in the observational data; the correlation coefficient between Tarfala summer temperature and winter balance over 1946-92 is -0.40 (slope $-0.144 \mathrm{~m}$ year $^{-1}{ }^{\circ} \mathrm{C}^{-1}$, intercept $2.25 \mathrm{~m}_{\text {year }}{ }^{-1}$ ). This relatively low correlation between $\Delta C$ and $\Delta T$ results in a large uncertainty in the slope of the regression; we therefore calculate reconstructions corresponding to forcings with (i) total independence between $\Delta C$ and $\Delta T$, (ii) some dependence governed by a slope of -0.14 $\mathrm{m}$ year ${ }^{-1} \mathrm{C}^{-1}$, and (iii) greater dependence governed by a slope of $-0.29 \mathrm{~m}_{\text {year }}^{-1}{ }^{\circ} \mathrm{C}^{-1}$. In each case, the average magnitude of the past accumulation from AD 500 to 1946 is adjusted, so that the glacier-volume reconstruction gives the correct volume in 1946 .

The resulting parameter sets we have chosen to use in this analysis are shown in Table 1. The parameter set S2 uses our central estimates for all the parameters. The sets $\mathrm{S} 1$ and S3 explore uncertainties in the relationship between $\Delta T$ and $\Delta C$, using the different forcings, $\mathrm{S} 4$ and $\mathrm{S} 5$ give a range for $m / n, \mathrm{~S} 6$ and $\mathrm{S} 7$ give a range for $h_{\mathrm{R}}^{*}$, S8 and S9 give a range for $\alpha$ (note that $T_{\mathrm{R}}$ has to be adjusted accordingly) and finally $\mathrm{S} 10$ and $\mathrm{S} 11$ give a range for $\beta$.

\section{d. Temperature sensitivity and response-time uncertainties}

The temperature sensitivity of glaciers is a critical issue in attempts to interpret past glacier changes in terms of climate and in trying to predict glacier (and hence sealevel) response to future climate change. The term, however, is not well defined in the literature, and there are different ways in which a temperature sensitivity may be defined. One form of temperature sensitivity is the mass-balance temperature sensitivity. In the present development, this is the parameter $\alpha\left(\mathrm{m}_{\text {year }}{ }^{\circ} \mathrm{C}^{-1}\right)$, which we take as a constant. In the palaeoclimate context, the glacier-length temperature sensitivity would be far more relevant. Here, the nearest we can get to this is the glacier-volume temperature sensitivity, a sensitivity that is fully appropriate in the sea-level context. This may be defined as (units, $\mathrm{m}^{3}{ }^{\circ} \mathrm{C}^{-1}$ or $\mathrm{cm}$ (sea-level equiv.) ${ }^{\circ} \mathrm{C}^{-1}$ ) $\mathrm{d} V / \mathrm{d} \Delta T$ where $\Delta T$ is the change in temperature at a fixed point relative to some reference value.

A little thought will show that this is not an immediately useful quantity. Glacier volume responds to climate in a way that is modified by glacier dynamics and $\mathrm{d} V / \mathrm{d} \Delta T$ is not a fundamental constant of the systemindeed $\mathrm{d} V / \mathrm{d} \Delta T$ may be positive or negative (as will be shown in the next section). The fundamental quantity that determines $\mathrm{d} V / \mathrm{d} \Delta T$ (through Equations (8) or (11)) is the equilibrium-volume temperature sensitivity, $\mathrm{d} V_{\mathrm{eq}} / \mathrm{d} \Delta T$.

To investigate the $\mathrm{d} V_{\text {eq }} / \mathrm{d} \Delta T$ sensitivity, we examine how $V_{\text {eq }}$ varies with summer temperature for the parameter values chosen for Storglaciären. These parameter sets are denoted S1-S11 and are tabulated in Table 1 , together with the corresponding glacier-response time at the reference volume. The variation of $V_{\mathrm{eq}}$ with summer temperature and the response time, which is dependent on volume, are important because together they determine the overall response of the glacier volume to temperature change (through Equation (11)).

We illustrate the results in Figure $4 \mathrm{a}$ and $\mathrm{b}$ for three values of the altitudinal accumulation gradient, $\beta$, denoted by parameter sets S10, S2 and S11. For a larger $\beta$, Figure 4a shows that $\mathrm{d} V_{\mathrm{eq}} / \mathrm{d} \Delta T$ is smaller and Figure $4 \mathrm{~b}$ shows that the response time is shorter. Other effects, not shown in Figure 4, are as follows: (1) The effect of the range of forcing options, $\mathrm{S} 1$ and $\mathrm{S} 3$, on $\mathrm{d} V_{\mathrm{eq}} / \mathrm{d} \Delta T$ is similar to that for $\beta$; the stronger the relationship between $\Delta T$ and $\Delta C$ the larger is $\mathrm{d} V_{\text {eq }} / \mathrm{d} \Delta T$. However, this set does not affect the response time. (2) The range of values of $m / n$, denoted by parameter sets $\mathrm{S} 4$ and S5, has a slightly larger effect compared to S10 and S11, smaller

Table 1. Glacier-model parameter values used for the reconstruction of Storglaciären AD 500-1992. The remaining reference parameters are $V_{\mathrm{R}}=3.04 \times 10^{8} \mathrm{~m}^{3}, A_{\mathrm{R}}=3.08 \times 10^{6} \mathrm{~m}^{2}$. Also shown are the assumed mean accumulation over AD 500-1946 and the model-derived value of the reference state response time $\left(\tau_{\mathrm{R}}\right)$

\begin{tabular}{|c|c|c|c|c|c|c|c|c|c|}
\hline & $\begin{array}{c}\text { Forcing } \\
\text { option }\end{array}$ & $m$ & $n$ & $\begin{array}{c}h_{\mathrm{R}}^{*} \\
\mathrm{~m}\end{array}$ & $\begin{array}{c}\alpha \\
\text { m year }^{-1}{ }^{\circ} \mathrm{C}^{-1}\end{array}$ & $\begin{array}{l}T_{\mathrm{R}} \\
{ }^{\circ} \mathrm{C}\end{array}$ & $\begin{array}{c}\beta \\
\text { year }^{-1}\end{array}$ & $\begin{array}{l}\text { Past } \overline{\Delta C} \\
\text { m year }^{-1}\end{array}$ & $\begin{array}{c}\tau_{\mathrm{R}} \\
\text { year }\end{array}$ \\
\hline $\mathrm{S} 1$ & (i) & 1.1 & 0.7 & 263 & 0.5 & 2.3 & 0.005 & 1.83 & 70 \\
\hline S2 & (ii) & 1.1 & 0.7 & 263 & 0.5 & 2.3 & 0.005 & 1.84 & 70 \\
\hline S3 & (iii) & 1.1 & 0.7 & 263 & 0.5 & 2.3 & 0.005 & 1.85 & 70 \\
\hline $\mathrm{S} 4$ & (ii) & 1.2 & 0.6 & 263 & 0.5 & 2.3 & 0.005 & 1.75 & 89 \\
\hline $\mathrm{S} 5$ & (ii) & 1.0 & 0.8 & 263 & 0.5 & 2.3 & 0.005 & 1.94 & 56 \\
\hline S6 & (ii) & 1.1 & 0.7 & 213 & 0.5 & 2.3 & 0.005 & 1.77 & 87 \\
\hline S7 & (ii) & 1.1 & 0.7 & 313 & 0.5 & 2.3 & 0.005 & 1.91 & 59 \\
\hline S8 & (ii) & 1.1 & 0.7 & 263 & 0.4 & 1.6 & 0.005 & 1.78 & 77 \\
\hline S9 & (ii) & 1.1 & 0.7 & 263 & 0.6 & 2.9 & 0.005 & 1.87 & 65 \\
\hline $\mathrm{S} 10$ & (ii) & 1.1 & 0.7 & 263 & 0.5 & 2.3 & 0.003 & 1.76 & 92 \\
\hline S11 & (ii) & 1.1 & 0.7 & 263 & 0.5 & 2.3 & 0.007 & 1.92 & 57 \\
\hline
\end{tabular}



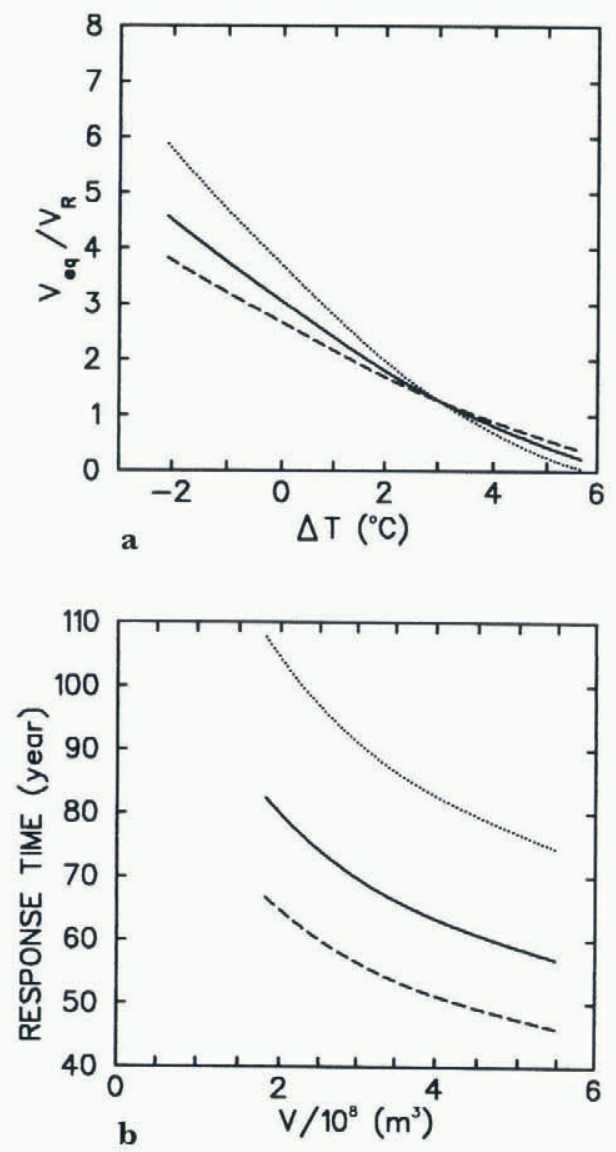

Fig. 4. (a) Plot of the equilibrium volume expressed as $V_{\mathrm{eq}} / V_{\mathrm{R}}$ versus $\Delta T$. The value of the reference lemperature $T_{\mathrm{R}}$ is set so that $\alpha \Delta T$ represents the ablation. The lines would cross at $V / V_{\mathrm{R}}=1$ for forcing option (i). (b) Plot of the response time, $\tau$, versus glacier volume. Both show resulls for a range of values for $\beta$, viz. 0.003 (dotted), 0.005 (solid), 0.007 (dashed) year ${ }^{-1}$ (i.e. parameter sets S10, 2 and 11 in Table 1).

$m / n$ giving smaller $\mathrm{d} V_{\mathrm{eq}} / \mathrm{d} \Delta T$ and shorter response times. (3) Different values of $h_{\mathrm{R}}^{*}$, represented by $\mathrm{S} 6$ and $\mathrm{S} 7$, have a slightly smaller effect than S10 and S1 1, larger $h_{\mathrm{R}}^{*}$ (lower altitude) implying smaller $\mathrm{d} V_{\text {eq }} / \mathrm{d} \Delta T$ and shorter response times. (4) Finally, the small uncertainly range for the parameter $\alpha$, represented by S8 and S9 (note also the different values for $T_{\mathrm{R}}$ ) give a smaller range, larger $\alpha$ giving a larger $\mathrm{d} V_{\mathrm{eq}} / \mathrm{d} \Delta T$ but shorter response times.

\section{e. The reconstruction over 1946-92}

We now examine the ability of the model to reconstruct the observed volume over 1946-92. For each parameter set, we have run the model from AD 500, adjusting the average accumulation over AD 500 to 1946 , so that the correct glacier volume is attained in 1946. The resulting values for the average past accumulation are given in Table 1. The values, which range from 1.75 to 1.94 $\mathrm{m}_{\text {year }}{ }^{-1}$, are higher than the mean value for 1946-92 of $1.43 \mathrm{myear}^{-1}$ but well within the range. Using these values for past accumulation, and the observed accumulation data over 1946-92, together with the temperature- dependent ablation throughout, the glacier volume over 1946-92 is almost exactly reproduced (Fig. 5a). This is simply because the mass-balance data are then accurately reproduced. When the observed accumulation data are used the $\beta\left(h_{\mathrm{R}}^{*}-h^{*}\right)$ term is omitted, since the data are already the required area averages.

Since for the past we only have the summertemperature data, it is interesting to see how well the model can perform without the recent accumulation data. Figure $5 b$ shows the results using the three forcing options: (i) $\Delta C$ independent of $\Delta T$, (ii) some dependence governed by a slope of $-0.14 \mathrm{~m}_{\text {year }}{ }^{-1}{ }^{\circ} \mathrm{C}^{-1}$, and (iii) greater dependence governed by a slope of $-0.29 \mathrm{~m}$ year ${ }^{1} \mathrm{C}^{-1}$ (i.e. parameter sets $\mathrm{S} 1-3$ (see section $4 \mathrm{c}$ )). The results show that only about a quarter of the observed declining glacier-volume trend can be explained by the warm temperatures and associated high ablation which is evident between 1946 and the early 1960s (Figs 2b and $3)$. The results indicate that the major part of the decline in volume was due to reduced accumulation/winter balance over approximately 1946-89. Figure 2a shows that greater accumulation has been observed in the most recent years and our adjusted past accumulations indicate that higher accumulation was also present for at least a few decades or so prior to 1946. It is also evident from Figure $5 \mathrm{~b}$ that the stronger the relationship between $\Delta C$ and $\Delta T$ the larger the amplitude of the glacier-volume variations but the declining trend is not materially affected.

In conclusion, we have shown that over 1946-92 changes in accumulation had an important influence on

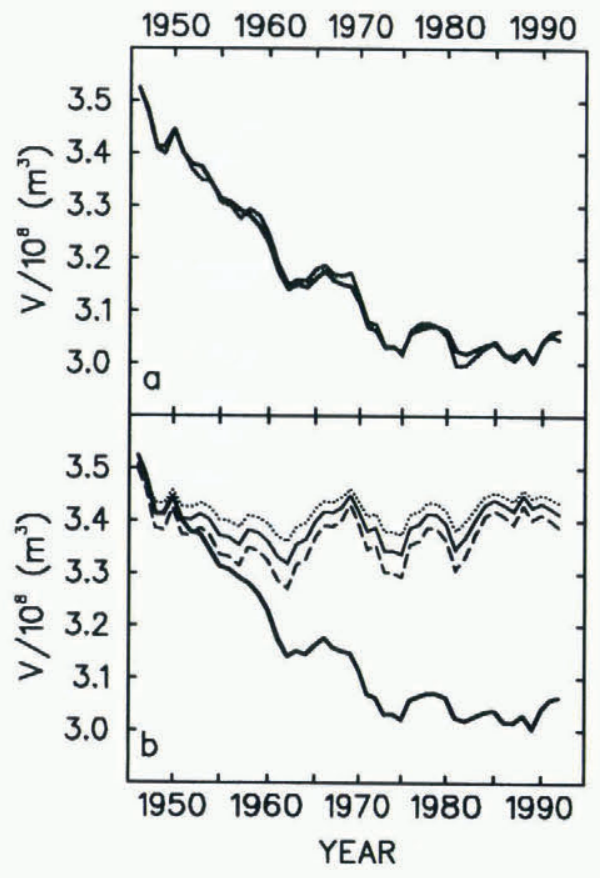

Fig. 5. (a) Observed (thick) and reconstructed volume for Storglaciären using the forcing options represented by parameter sets $\mathrm{S1}-3$ (see Table 1), including observed accumulation over 1946-92. (The three reconstructions are indistinguishable.) (b) Same as (a) but excluding observed accumulation over 1946-92. Forcing option (i) dotted, (ii) solid, (iii) dashed. The reconstructions commenced in AD 500 . 
glacier volume. Whether changes in accumulation are equally important on longer time-scales cannot be determined from this analysis but, since we only have a past summer-temperature record for making the reconstruction, the possible concomitant effects of accumulation changes should be borne in mind when comparisons are made with other proxy evidence.

\section{A 1493 YEAR HISTORY OF STORGLAGIÄREN}

We take the glacier-volume reconstruction using parameter set S2 as our central estimate. To indicate the range of uncertainty, we also carry out a set of runs with the other parameter settings, as shown in Table 1. In addition, we use three different starting values (discussed below) giving a total of 33 runs. In all cases, the model was forced with the composite reconstructed/ observed summer-temperature record. The temperature forcing and the range of responses are shown in Figure 6 and the results are discussed in detail below.

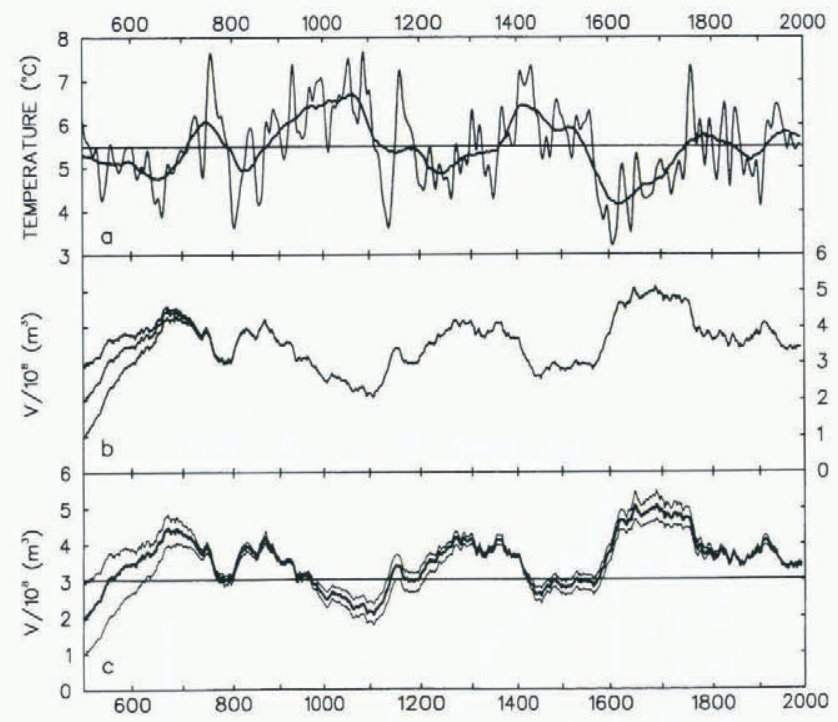

Fig. 6. (a) Extended Tarfala temperature series based on the northern Fennoscandian temperature reconstruction of Briffa and others (1992). Although the model is forced with annual data, we show the data smoothed to emphasize $<25$ year and <200year fluctuations. (b) Glacier reconstruction from AD 500 with three alternative initial volumes. (c) Glacier reconstructions from AD 500. The thick line uses parameter set S2 in Table 1. Also shown is the range obtained using $S 1-11$ with three alternative starting volumes (33 runs).

\section{a. Comparison with a previous reconstruction}

We begin by comparing reconstructed data from 1878 with the reconstruction of Holmlund (1987). Holmlund estimated changes in the volume of Storglaciären back to 1878 by regressing the mass-balance data against summer temperatures at Karesuando. Here, we compare our glacier reconstructions with Holmlund's cumulative massbalance change estimates.

The correlation coefficient between the extended
Tarfala temperature series and the Karesuando data for June-August over 1860-1992 is 0.80 and we find that glacier reconstructions using a temperature series for Karesuando extended back to AD 500 are not significantly different from those using the extended Tarfala series. We are therefore justified in comparing our reconstructions with Holmlund's directly, as shown in Figure 7.

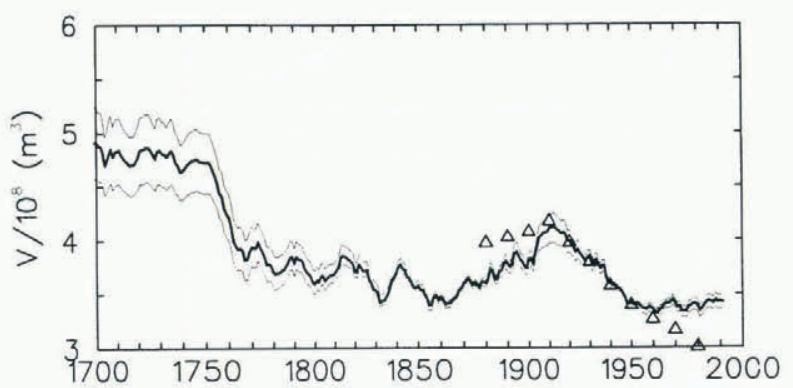

Fig. 7. Reconstructed volumes from 1700 using parameter sets as in Figure 6c. The triangles are taken from the regression-based reconstruction of Holmlund (1988).

There are differences between our temperature-based reconstruction and that of Holmlund (1987) both before 1910 and after 1946 which we seek to explain. For the period 1910-46 both the Karesuando summer-temperature series and the extended Tarfala record have an increasing linear trend in temperature of about $0.03^{\circ} \mathrm{C}$ year ${ }^{-1}$ but after 1946 there are subtle differences between the series. For 1946-92, the Karesuando series has a small positive trend of $0.003^{\circ} \mathrm{Cyear}^{-1}$, whereas the Tarfala series has a negative trend of $-0.02^{\circ} \mathrm{C}_{\text {year }}{ }^{-1}$ (see Figure 3 and the attendant decrease in ablation shown in Figure $2 \mathrm{~b}$ ). From comparisons of reconstructions using our model forced with both series, we find that this trend difference can only explain a small part of the difference between our reconstruction and Holmlund's over 1946 92. The main reason for the difference is that Holmlund chose his regression constants relating mass balance to summer temperature so as to reproduce the predominantly negative mass balance over 1946-92 (Fig. 2c), assuming constant accumulation. However, our evidence suggests that the negative mass balance over this period was not primarily a result of warm temperatures but rather a result of relatively low accumulation (see section $4 \mathrm{e}$ ).

The agreement between our reconstruction and that of Holmlund over 1910-46 must therefore be the result of compensating influences. For example, the difference which is expected in the temperature forcing could be compensated by the fact that Holmlund assumed constant accumulation, whereas we assume higher accumulation before 1946. In addition, the differences in the methods used to account for changes in the glacier area are likely to have some effect.

The summer temperature trends over the period 1878-1910 are $-0.025^{\circ} \mathrm{C}_{\text {year }}^{-1}$ for the extended Tarfala series and $-0.018^{\circ} \mathrm{C}_{\text {year }}{ }^{-1}$ for the Karesuando series. In addition to the accumulation assumptions, this difference may be a factor causing the two reconstructions to diverge again before 1910. However, an important factor must also be that, in the real world, the glacier volume is 
influenced by the climate history (automatically included in our model) and not just by the contemporaneous climate (as Holmlund's reconstructions assume). Since it is the climate history which determines the glacier area and volume, it is therefore only possible to reconstruct glacier changes forward in time. This fact is clearly demonstrated below where we consider the effect of choosing different starting volumes in AD 500.

\section{b. Sensitivity to initial glacier volume}

To reconstruct the glacier volume over AD 500-1992, the initial glacier volume, $V_{500}$, must be assigned a value. We take as a central value $2.0 \times 10^{8} \mathrm{~m}^{3}$, chosen on the basis of an independent, unpublished reconstruction of summer temperatures over the period from AD 1 (for a mean June and July season based solely on ring-width data). These earlier temperature estimates indicate distinctly warm conditions between about AD 350 and 500 (particularly during the two decades before 500 ). This strongly suggests a $V_{500}$ estimate below present-day levels. To represent the uncertainty associated with the choice of starting volume, we also consider $V_{500}$ values of $1.0 \times 10^{8} \mathrm{~m}^{3}$ and $3.0 \times 10^{8} \mathrm{~m}^{3}$. The results (Fig. $6 \mathrm{~b}$ ) show that the influence of the initial volume gradually diminishes and becomes negligible after a period of about 200 years.

\section{c. Comparison with historical and geomorph- ological evidence}

Figure 6c illustrates our reconstructed history of Storglaciären volume over the period AD 500-1992. The "uncertainty" band represents the range of results produced by all of the 33 individual model runs described in Table 1 S1-S1l, each with three starting volumes). The following discussion relates to the S2 reconstruction as indicated by the bold line. Again, we stress that these results reflect the temperature-dependence in changing glacier volume and it should be borne in mind that our results for the post-1946 period emphasize the importance of accumulation. Temperature variability displays much greater spatial coherence than precipitation so that differences in glacier response within a region are likely to be due to localized precipitation anomalies. Specific glacier dynamics are of course also important.

A body of historical evidence has established that Scandinavian glaciers in general reached very advanced positions in the 18th century (in some cases their most advanced positions for the whole post-glacial period) (Eide, 1955; Karlén, 1988; Matthews, 1991; Bickerton and Matthews, 1993). Many southern glaciers have retreated, with minor re-advances, ever since. Others in northern Scandinavia, including Storglaciären, show a major re-advance at the beginning of the 20th century. Some northern Swedish glaciers even attained their maximum Neoglacial positions at this time (e.g. Rabots Glacier around 1916; Karlén, 1973). The Storglaciären terminus in 1916 was nearly as advanced as it was in the first half of the 18th century (Karlén, 1973).

These dates agree well with the timing of the maximum glacier volume attained in our Storglaciären model results between about 1650 and 1750 and with the subsequent declining volume trend, especially since one might expect a phase difference between volume and length change. Our results also show a recurrence of increasing glacier volume starting in 1860 and culminating in a 20th century volume peak at about 1915, again in good agreement with the historical evidence. However, the difference in glacier volume between the first half of the 18th century and 1915 is larger than suggested by the moraine evidence. Changes in accumulation could account for this disparity. For example, over the cold period from about 1570 to 1740 , the mean accumulation used to produce our S2 reconstruction is 8\% higher than the assumed mean (1.84 mear $^{-1}$ ) over AD 500-1946 due to the inverse relationship between summer temperature and accumulation (i.e. forcing option (ii) in Table 1). If, instead of this high accumulation over 1570-1750, we assume a mean value similar to that observed over 19461992 (viz. $1.43 \mathrm{~m}$ year $^{-1}$ ) the maximum volume attained in the 18th century is similar to that reached around 1915.

There has been some dispute about the timing of the onset of the major glacial expansion that culminated in the mid 18th century. The tree-ring-based temperature reconstruction shows an abrupt and precipitous fall occurring around 1570. Starting from this date, the modelled ice volume rises dramatically from a value around $2.9 \times 10^{8} \mathrm{~m}^{3}$ to a peak of about $5.0 \times 10^{8} \mathrm{~m}^{3}$ around 1650 , an increase of $2.1 \times 10^{8} \mathrm{~m}^{3}$ in only 80 years. These results support a late 16 th century date for the commencement of this phase of Scandinavian glacial expansion, as proposed by Hoel and Werenskiold (1962) for Norway. However, changes in accumulation may have modified the response for Storglaciären.

For the earlier part of the record, Karlén (1988) drew attention to a range of radiocarbon, lichenometric and lacustrine evidence from different Scandinavian sources, all of which indicate general glacier advances between about AD 550 and 970. Our results indicate that ice volumes were above present-day levels from around AD 560 to 770 and $\mathrm{AD} 790$ to 960 , with local ice-volume maxima occurring around AD 670 and 870. The peak in $\mathrm{AD} 670$ is the second highest volume achieved in the 1483 year reconstruction.

We also reconstruct a long period of melting beginning about AD 870 in response to anomalously warm temperatures which began at around this time. The warmth persisted until about 1100 by which time the volume is estimated to have fallen to around $2.1 \times 10^{8}$ $\mathrm{m}^{3}$, about two-thirds of its current volume. This is the smallest volume attained in the 1493 years modelled. Cooler conditions returned in the first half of the 12th century, arresting the decline. Given the lack of knowledge about accumulation, even smaller volumes may have occurred at that time but experimenting with reduced accumulation our model results suggest that it would have required a decrease in the mean accumulation of at least $90 \%$ below the assumed value, for many preceding decades, to have resulted in the disappearance of the glacier. Thus, our results accord with evidence that Storglaciären has existed continuously for at least 2000 years (i.e. ${ }^{14} \mathrm{C}$ dated $\mathrm{CO}_{2}$ in terminus ice measured by Denton and cited by Karlén (1973)).

Even though the second half of the 12 th century was 
relatively warm, this warmth produced only a minor suppression in the general ice expansion that occurred through the 12 th and 13 th centuries. This expansion continued, with minor fluctuations, in response to a period of generally cool conditions until the volume reached a peak in the second half of the 13th century and again in the $1350 \mathrm{~s}$. The reconstructed volume at those times is similar to that for 1915. Interestingly, Karlén (1988) noted historical and lacustrine evidence which implies the culmination of a general glacier advance between 1350 and 1400, though the historical evidence (Eide, 1955) has been disputed (Grove, 1985, 1988).

\section{d. Discussion relevant to climate and/or glacier reconstruction}

Our results illustrate the difficulties in the climatic interpretation of glacial moraine data. First, it is clearly important to account for lags in the glacier response to climate. On average, the lag between the filtered temperature forcing and our reconstructed glacier response for Storglaciären is about 40 years (slightly greater than half the glacier-model response time). A detailed examination of the temperature forcing and glaciermodel results shows that the lags vary and depend in a complex way on the history of the forcing over a range of time-scales. Secondly, it is clear that the timing and magnitude of the temperature forcing cannot be deduced on the basis of moraine stratigraphic evidence alone. Thirdly, the relatively long glacier-response times and the limitations of traditional dating techniques mean that important temperature oscillations occurring on timescales of less than a century are virtually undetectable by traditional moraine dating. Finally, changes in accumulation have a significant effect.

The lack of any obvious decadal response and the variable lags for the century time-scale response mean that the concept of a glacier-volume temperature sensitivity is of limited value. Although our results show that, in general, the glacier-volume changes mirror the temperature changes, because of the long response time, the magnitude of $\mathrm{d} V / \mathrm{d} \Delta T$ is variable and though usually negative it is even on occasion positive. As noted in the previous section, the more fundamental quantity is the equilibrium volume temperature sensitivity, $\mathrm{dV}_{\text {eq }} / \mathrm{d} \Delta \mathrm{T}$. This quantity cannot be estimated directly from $\mathrm{d} V / \mathrm{d} \Delta T$. It can only be obtained from glacier-volume data with a model and even then it is dependent on the accumulation.

\section{CONGLUSIONS}

A simple geometric model of changing glacier volume has been derived. The model equations may be expressed in terms of the equilibrium glacier volume and a response time. We show that the expression for the latter is similar to one previously derived by Jóhannesson and others (1989a) and Paterson (1994).

We have applied the glacier model to Storglaciären. Using data from Tarfala Research Station over 1946-92, the summer temperature forcing has been extended back to $\mathrm{AD} 500$, based on a tree-ring-derived series for northern
Fennoscandia (Briffa and others, 1990, 1992). We have had to make some assumptions about past accumulation forcing.

For a range of forcing options and parameter settings, we have adjusted the average past accumulation so that, starting in AD 500, the correct glacier volume is reconstructed at the start of the observational record in 1946. An important result of our analysis is that pre-1946 accumulation must have been substantially higher than the mean over 1946-92 and more in line with the higher values observed since 1989. Given the higher pre-1946 accumulation, the accumulation between 1946 and 1989 was relatively low. We show that it is this low accumulation which was the primary cause of the reduction in volume of Storglaciären over this period rather than warm temperatures as was previously supposed.

Our reconstruction of a high glacier volume around 1916 agrees well with the previous reconstruction of Holmlund (1987) which is backed up by photographic evidence. However, we argue that this agreement is in part a result of compensating influences.

The maximum glacier volume attained in our 1493 year reconstruction occurs between 1650 and 1750. This agrees with the historical evidence that Scandinavian glaciers in general reached very advanced positions in the 18th century. However, in order to fit in with the moraine data which show that the volume of Storglaciären in the 18th century was not much larger than around 1916 (Karlén, 1973), accumulation in the cold period between 1580 and 1740 must have been fairly low, perhaps similar to that observed over 1946-92. Thus, our results support Holmlund's (in press) suggestion that during cold periods of the Holocene the precipitation rate tended to be low.

The smallest ice volume in our reconstruction was attained in about 1100 . Even taking into account possible accumulation changes, our results accord with evidence that Storglaciären did not disappear at this time (Karlén, 1973).

Our model clearly demonstrates the difficulty in direct interpretation of glacier-movement evidence in terms of past climates. Because of the glacier-response time, the glacier acts as a non-linear low-pass filter. This also introduces a lag between climate forcing and glacier response which itself depends on the previous climate history.

We have argued and demonstrated that volume sensitivity to temperature change, $\mathrm{dV} / \mathrm{d} \Delta T$, can be misleading and that a more fundamental sensitivity is the equilibrium volume sensitivity, $\mathrm{dV}_{\text {eq }} / \mathrm{d} \Delta T$. However, both are effected by accumulation.

The present work shows the importance of accumulation changes and lays the foundation for studies of past precipitation and for attempts to reconstruct glacier behaviour in northern Fennoscandia during the last 7000 years.

\section{AGKNOWLEDGEMENTS}

The authors would like to thank W. Karlén for providing the Storglaciären mass-balance and climate data and for helpful discussions and encouragement during the course 
of the work. A. Hall, J. Matthews, M. Meier and R. van de Wal also provided advice and/or comments on the original manuscript. Referees' comments have led to substantial improvements. In particular, the authors wish to thank T. Jóhannesson for his interest and subsequent extensive correspondence which lead to improvements in the model and a reworking of the manuscript. This work was supported by the C.E.C. under grants EV5V-CT91-0051 and EV5V-CT94-0050, the U.K. Natural Environment Research Council under grant GST/02/498 and by the U.S. Department of Energy under grant DE-FG0286ER60397.

\section{REFERENCES}

Bickerton, R. W. and J. A. Matthews, 1993. "Little Ice Age" variations of outlet glaciers from the Jostedalsbreen ice-cap, southern Norway: a regional lichenometric-dating study of ice-marginal moraine sequences and their climatic significance. 7. Quat. Sci., 8 1), 45-66.

Bodin, A., ed. 1993. Tarfala research station. Annual report, 1991-1992. Stockholm, Stockholms Universitet. Naturgeografiska Institutionen. (Forskningsrapport 96.)

Briffa, K. R. and 6 others. 1990. A 1,400-year tree-ring record of summer temperatures in Fennoscandia. Nature, 346 6283), 434439.

Briffa, K. R. and 7 others. 1992. Fennoscandian summers from A.D. 500: temperature changes on short and long timescales. Climale Dyn., 7, $111-119$.

Eide, T. O. 1955. Breden og bygda. Norsk Tidsskr. Folkelivsgransking, 5, 1-42. Greuell, W. 1992. Hintereisferner, Austria: mass-balance reconstruction and numerical modelling of the historical length variations. $\mathcal{f}$. Glaciol., 38 (129), 233-244.

Grove, J. M. 1985. The timing of the Little Ice Age in Scandinavia. In Tooley, M.J. and G. M. Sheail, eds. The climatic scene. London, George Allen and Unwin, 132-153.
Grove, J. M. 1988. The Litlle Ice Age. London and New York, Methuen. Hocl, A. and W. Werenskiold. 1962. Glaciers and snowfields in Norway. Nor. Polarinst. Skr. 114.

Holmlund, P. 1987. Mass balance of Storglaciären during the 20th century. Geogr. Ann., 69A(3-4), 439-447.

Holmlund, P. 1988. Is the longitudinal profile of Storglaciären, northern Sweden, in balance with the present climate? f. Glaciol., 34(118), $269-273$.

Holmlund, P. In press. Climatic influence on the size of glaciers in northern Scandinavia during the last two centuries. In Holocene glacier fluctuations in Europe. Proceedings of the ESP Workshop, March 1991, Zürich.

Holmlund, P. and M. Eriksson. 1989. The cold surface layer on Storglaciären. Geogr. Ann., 71A (3-4), 241-244.

Jóhannesson, T., C.F. Raymond and E. D. Waddington. 1989a. A simple method for determining the response time of glaciers. In Oerlemans, J., ed. Glacier fluctuations and climatic change. Dordrecht, etc., Kluwer Academic Publishers, 343-352.

Jóhannesson, T., C. Raymond and E. Waddington. 1989b. Time-scale for adjustment of glaciers to changes in mass balance. \%. Glaciol., 35 (121), 355-369.

Karlén, W. 1973. Holocene glacier and climatic variations, Kebnekaise mountains, Swedish Lapland. Geogr. Ann., 55A (1), 29-63.

Karlén, W. 1988. Scandinavian glacial and climatic fluctuations during the Holocene. Quat. Sci. Rev., 7 2), 199-209.

Kuhn, M. 1981. Climate and glaciers. International Association of Hydrological Sciences Publication 131 (Symposium at Canberra 1979 - Sea Level, Ice and Climatic Change), 3-20.

Matthews, J.A. 1991. The late Neoglacial ('Little Ice Age') glacier maximum in southern Norway: new ${ }^{14} \mathrm{C}$-dating evidence and climatic implications. The Holocene, 1, 219-233.

Oerlemans, J. 1992. Climate sensitivity of glaciers in southern Norway: application of an energy-balance model to Nigardsbreen, Hellstugubreen and Alfotbreen. J. Glaciol., 38 (129), 223-232.

Paterson, W.S. B. 1994. The physics of glaciers. Third edition. Oxford, etc., Elsevier.

Schytt, V. 1981. The net mass balance of Storglaciären, Kebnekaise, Sweden, related to the height of the equilibrium line and to the height of the $500 \mathrm{mb}$ surface. Geogr. Ann., 63A (3-4), 219-223. 